Images dans le monde ibérique et ibéricoaméricain

$8 \mid 2015$

L'Histoire et ses récits entre images, fictions et paratextes

\title{
Conflicto por el sentido: Siete Partidas en su edición de 1555
}

\section{Daniel Panateri}

\section{(2) OpenEdition \\ Journals}

Edición electrónica

URL: http://journals.openedition.org/agedor/441

DOI: $10.4000 /$ agedor.441

ISSN: 2104-3353

\section{Editor}

Laboratoire LISAA

Referencia electrónica

Daniel Panateri, «Conflicto por el sentido: Siete Partidas en su edición de 1555 », L'Âge d'or [En línea], 8 | 2015, Publicado el 01 febrero 2016, consultado el 10 diciembre 2020. URL : http://

journals.openedition.org/agedor/441 ; DOI : https://doi.org/10.4000/agedor.441 


\title{
Conflicto por el sentido: Siete Partidas en su edición de 1555
}

\begin{abstract}
Resumen: Le discours juridique constitue l'un des éléments fondamentaux dans l'analyse du développement politique. Le Moyen Âge tardif est la période centrale durant laquelle se développe ce discours, et son étude permet donc d'aboutir à des conclusions fondamentales sur la relation entre la construction idéologique de l'État et sa réalité matérielle.

Dans ce contexte, le cas castillan est exemplaire. Le travail législatif d'Alfonso $\mathrm{X}$ et son principal ouvrage, Siete Partidas, constituent un jalon juridique et politique important pour le XIIIe siècle. De fait son examen, dans ce cas précis joint à l'apparat critique de gloses du XVIe siècle, fournit une constante et, à ce jour, inépuisable source d'éléments qui nous permettent de retracer les concepts juridiques centraux du discours politique qui se met en place au XIII e siècle. Ainsi, notre propos est d'analyser comment la glose de López a influencé la façon dont ont été lus certains concepts de l'œuvre cidessus mentionnée.
\end{abstract}

Mots-cles: Siete Partidas - Glose juridique - Resémantisation - Conflit - Relocalisation de sens - Droit médiéval - Politique

Resumen: El discurso jurídico constituye uno de los elementos fundamentales para el análisis del desarrollo político. La baja Edad Media es el momento central en el avance de dicho discurso y, por lo tanto, su estudio constituye la posibilidad de lograr conclusiones fundamentales sobre la relación entre la construcción ideológica del Estado y su realidad material. El caso castellano, en este contexto, resulta paradigmático. La labor legislativa de Alfonso X y su principal producto, Siete Partidas, constituyen un hito jurídico político para el siglo XIII. En rigor, su examen, en este caso junto al aparato de glosas del siglo $\mathrm{XVI}$, provee una constante $\mathrm{y}$, hasta ahora, inagotable fuente de elementos que nos permiten rastrear conceptos jurídicos centrales del discurso político que se pone en marcha en este mismo siglo XIII. De tal modo, nuestra propuesta es analizar cómo la glosa de López influyó en la manera que se leyeron algunos conceptos de la mencionada obra.

Palabras clave: Siete Partidas - Glosa jurídica - Resemantización - Conflicto - Relocación de sentido Derecho medieval - Política

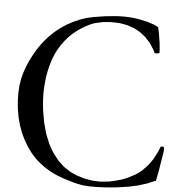

omo dijera Pérez Martín, resulta imprescindible para un historiador del derecho el diálogo constante con la Filología, «ya que el Derecho se nos ha transmitido fundamentalmente en textos» ${ }^{1}$ y para su interpretación nos es necesaria dicha disciplina $^{2}$. En definitiva, ponderamos que es necesario establecer una perspectiva filológica para el estudio de fenómenos jurídicos. En este sentido, el propósito actual de nuestro estudio es el de mostrar la manera en la que la glosa jurídica del editor de Partidas de 1555, Gregorio López, funcionó como un elemento de resemantización por medio del cambio de

\footnotetext{
1 PÉREZ MARTÍN, Antonio, «Glosas medievales a textos jurídicos hispánicos. Inventario y tipos», in Cahiers de linguistique hispanique médiévale, 14-15, 1989, p. 17.

2 Cf. GIBERT, Rafael, «La Historia del Derecho como historia de los libros jurídicos», in I seminario de Historia del Derecho y Derecho Privado. Nuevas técnicas de investigación, Bellaterra, Universidad Autónoma de Barcelona, 1985, p. 61-92.
} 
foco operado sobre la materialidad de la obra por un lado, y la discusión abierta de algunos supuestos políticos alfonsíes por el otro ${ }^{3}$. La exposición se encadenará del siguiente modo: en primer lugar expondremos brevemente la relación entre escritura marginal y Derecho con el fin de demarcar claramente nuestra perspectiva; en segundo lugar, expondremos un breve análisis formal del texto fuente Las Siete Partidas con el objetivo de asentar la semántica probable que será objeto de conflicto en la glosa posterior, y finalmente, mostraremos el funcionamiento de la ponderada glosa como resemantizadora.

\section{El margen en las fuentes jurídicas}

Las «simples» anotaciones marginales pueden ser un objeto de estudio que plantee mayores interrogantes, y respuestas en más de un caso, que el propio texto que comenta. En este sentido, los últimos años han visto una profusión de trabajos al respecto, sean sobre Marginalia, comentarios en general o glosas de cualquier tipo ${ }^{4}$. Esto no solo nos habla del valor históricoliterario de este fenómeno sino también de la necesidad de dejar descansar a textos ya revisitados para retomarlos desde otra perspectiva.

Desde este punto de vista, podemos afirmar que la glosa es el género jurídico literario más importante en el mundo del derecho medieval, a tal punto que es el que da origen a los demás (apostillas, comentarios, sumas, quaestiones, dissensiones dominorum, notabilia, etc.). El punto de partida estuvo en los pequeños textos que originalmente se recostaban en los márgenes de los códigos legales y tenían como objetivo explicarlo, aclararlo, etc. A su vez, el apparatus será la exposición más o menos uniforme de una serie de glosas a un texto jurídico determinado. Ahora bien, si este fue el objetivo inicial de la glosa, la práctica en sí misma rindió frutos enormes y llevó a dicha práctica a constituirse como un género complejo donde la variabilidad de formas y contenido alcanzó movimientos autónomos y condujo a que se constituyera como un objeto de alcance pedagógico, editorial y, fundamentalmente, de construcción y dinamización sistemática del derecho medieval. Para los textos antiguos (fundamentalmente el Corpus Iuris Civilis, el Corpus Iuris Canonici, pero también los iura propia), ya caducos en parte, la glosa fue la manera de adaptar, reinventar, las compilaciones legales para la sociedad propia en la que al jurista le preocupaba intervenir. De este modo, la glosa comporta al menos dos fines para quienes la realizaban: uno especulativo, la comprensión del propio texto jurídico base y otro práctico, la resolución de conflictos concretos que se presentaban en la sociedad. La glosa pone en evidencia, intentando eliminarlo, el inmovilismo de la letra jurídica frente a la sociedad cambiante que busca organizarse a través de ella.

\footnotetext{
${ }^{3}$ Las Siete Partidas del sabio rey don Alfonso el nono. Nuevamente glosadas por el licenciado Gregorio Lopez del Consejo Real de Indias de su Majestad, Salamanca, 1555 [edición de Gregorio López en reproducción anastática del Boletín Oficial de Estado, 1974].

${ }^{4}$ Solo a modo de ejemplo: HEUSCH, Carlos, «La morale du Prince Charles de Viana», in Atalaya, 4, 1993, p. 93-226. DAGENAIS, John, The Ethics of Reading in Manuscript Culture: Glossing the 'Libro de Buen Amor", New Jersey, Princeton University Press, 1994. WEISS, Julian, «Las fermosas e peregrinas ystorias: sobre la glosa ornamental cuatrocentista», in Revista de Literatura Medieval, 2, 1990, p. 103-112. LUCÍA MEGÍAS, José Manuel, «Notas de la recepción de Lanz̧arote del Lago», in Verba Hispánica, IV, 1994, p. 83-96. HOOK, David, «Method in the Margins: An Archeology of Annotation», in Proceedings of the Eight Colloquium, Londres, Department of Hispanic Studies, Queen Mary and Westfield College, 1997, p. 135-144. JACKSON, H. J., Marginalia. Readers writing in books, New Haven, Yale University Press, 2001. FRADEJAS RUEDA, José Manuel, «Las glosas de San Cristóbal a la versión castellana de la Epitome rei militaris», in Incipit, XXIX, Buenos Aires, Secrit, 2009, p. 57-72. RODRÍGUEZ VELASCO, Jesús, «La Bibliotheca y los Márgenes. Ensayo teórico sobre la glosa en el ámbito cortesano del siglo XV en Castilla. I: Códice, dialéctica y autoridad», in eHumanista, 1, 2001, p. 119-134. RODRÍGUEZ VELASCO, Jesús, «La producción del margen», in La Corónica, 39, 1, 2010, p. 249-72. RODRÍGUEZ VELASCO, Jesús, Plebeyos Márgenes. Ficción, Industria del Derecho y Ciencia Literaria (siglos XIII-XIV), Salamanca, SEMYR, 2011, entre otros.
} 
A la hora de explicar por qué estudiar las glosas, resalta además un hecho muy simple: todavía aun resulta una terra ignota. El empuje primigenio estuvo en el trabajo excepcional que desde el Max-Planck-Institut fuer Europaeische Rechtsgeschichte de Frankfurt (Main) vienen realizando varios especialistas de renombre 5 .

Más allá de revitalizar el valor de la escritura marginal, debemos incorporar su diversidad. Comencemos con una taxonomía central y que hace referencia a su forma y utilización. En primer lugar, están las llamadas glosas interlineales. Como su nombre lo indica se encuentran dentro de la caja del texto y se ubican encima de las palabras fuente. No constituyen la mayoría y tratan de enmendar palabras mal transcritas o de agregar omisiones del copista. Es una obviedad decir que la referencia al texto resulta excluyente. Dicha forma de glosa no tiene prácticamente existencia dentro del mundo jurídico hispánico, ya que este estadio rudimentario ya había sido sobrepasado al momento del inicio de la actividad glosadora en la Península Ibérica ${ }^{6}$. En segundo lugar, encontramos las «clásicas» glosas marginales. Éstas también tienen cierta dependencia del texto fuente. La manera tradicional de marcarlas es a través de una «llamada» dentro de la caja del texto o subrayando la palabra a glosar. La tercera, es la glosa que se coloca inmediatamente al final del texto, cada ley o fuero. Esta forma es rara en los manuscritos y más común en los impresos posteriores; tendrían un origen de glosa marginal. Finalmente, existen glosas independientes. Este tipo de glosas no dejan de tener una dependencia relativa al texto fuente, pero se plantean como una unidad de interpretación con valor propio.

Ahora bien, también podemos plantear una tipología sobre la base del contenido. En primer lugar, glosas que tienen como única meta corregir al texto fuente. Bien podrían ser las que denominamos interlineales y tienden a ser acotadas y específicas. Las más útiles, aunque menores en número, son las que señalan variantes entre los manuscritos que ya circulaban en la época de ese copista. La intención es la estabilización del texto meta con plena conciencia de los problemas que la circulación conllevaba. En segundo lugar, glosas que se proponen esclarecer pasajes oscuros o simplemente engrandecer el original a través de la aseveración del contenido. A su vez, las glosas pueden ser puramente alegaciones o extractos de otras obras, haciendo que dos o más textos se pongan en juego. Finalmente, encontramos aquellas que podemos llamar glosas interpretativas. En este procedimiento se intenta exponer una reflexión sobre el texto fuente que sea acorde al receptor de esa actualidad. Asimismo, la variabilidad de extensión y contenido no hace más que señalar lo complejo y arduo de este trabajo. Esto puede ir desde unas escasas líneas hasta lo que llamaremos «mini tratados» de varios folios completos. Para los textos jurídicos hispánicos, además de la obra que nosotros trataremos esta forma tan rica de glosa se encuentra en la de Arias de Balboa al Ordenamiento de Alcalá (con respecto a la nulidad de las sentencias) y en la de Pertusa al Fori Aragonum (con respecto a los derechos de la viuda, duelos, etc.). En general, a medida que la fecha de composición se retrasa estos «mini tratados» resultan cada vez más comunes. Aunque, debemos agregar, no todos tendrán la misma magnitud e importancia.

Weiss divide las formas de «interrupción textual» en tres tipos ${ }^{7}$ las breves anotaciones que se intercalan en el propio texto o se ubican al margen «to provide the minimum of information necessary to understand the text and grasp at least a small part of intellectual or literary background. Thus they offer concise explanations of historical or mythological references, of etymologies and sourcess. ${ }^{8}$. Las marginalia donde no prima la pequeña información para clarificar cuestiones concretas, sino que aparecen «to

\footnotetext{
5 Nos referimos brevemente a los estudios sobre la glosa preaccursiana de DOLEZALEK, Gero, «Azos Glossenapparat zum Infortiatum», in Ius commune, 3, 1970, p. 186-207, DOLEZALEK, Gero, Repertorium manuscriptorum veterum Codicis Iustiniani, Francfort del Meno, Klostermann, 1985, y VAN DE WOUW, Hans, «Zur textgeschichte des Infortiatum und zu seiner Glossierung durch die fruehen Bologneser Glossatoren», in Ius commune, 11, 1984, p. 231-280, entre otros.

${ }^{6}$ PÉREZ MARTÍN, Antonio, Glosas medievales a textos jurídicos hispánicos, op. cit., p. 32.

7 WEISS, Julian, The poet's Art. Literary Theory in Castile c. 1400-1600, Oxford, Oxford University Press, 1990.

8 «para proveer el mínimo necesario de información para poder entender el texto y comprender al menos una pequeña parte del trasfondo intelectual y literario. Por lo tanto, ellas [las glosas] ofrecen explicaciones concisas sobre referencias históricas y mitológicas, de etimologías y fuentes», ibid, p. 122.
} 
paraphrase and summarize the author's main arguments». Finalmente, partiendo del punto anterior y manteniendo la pretensión de elucidar oscuridades del texto fuente, pero sin subordinarse al texto glosado como los casos anteriores, aparecen glosas con un formato más discursivo y mayor extensión donde la intención ya no es acompañar al lector por el texto fuente sino reubicarlo en «the wider realms of historical and literary discussion or philosophical speculation» ${ }^{10}$. Podemos afirmar que este último tipo de glosa será la que nos interese. En primer lugar, porque su extensión revela una práctica nueva. En segundo lugar, porque la intención de una glosa de este tipo no solo nos habla de la recepción, sino también de las razones para la reedición de Partidas y del funcionamiento esperado para un código legal del siglo XIII en el siglo XVI. Por último, entendemos que la relación entre la extensión y la intención produce un cambio cualitativo (intelectual y material) sobre la lectura y, primordialmente, sobre el sentido de la misma. Esto nos habla de una hermenéutica que se abre paso con el fin de poseer una entidad que, en términos reales, ha sido vaciada de contenido.

El comentario marginal del editor guadalupano se inscribe en una obra que no hay que adaptar, sino que hay que llenar. Esta condición de Partidas plantea para toda la actividad glosadora dedicada a ella una serie de condicionamientos que la hacen salir de las prácticas tradicionales. Con mayor énfasis aún, la glosa de Gregorio López viene a llenar el vacío jurídico de una obra legislativa que es promulgada para llenar a la vez un vacío político ${ }^{11}$.

Debemos posicionarnos en otro plano que el de la historia intelectual. Aquí lo que se produce es un cambio sobre la materialidad del texto. Se produce una reconfiguración espacial del sentido por medio de la "relocación" desde la lectura central hacia el margen. Es una palabra de otro (nueva) en un texto lejano (por diversas circunstancias) y que produce un reordenamiento, cuando no fagocitación, del texto original con implicaciones jurídico-políticas concretas. Sin negar el lugar supletorio, el glosador hace de la ficción el fundamento de la creatividad jurídica. Esta capacidad única del Derecho, junto con su lenguaje propio, establece el parámetro para su autopoiesis $^{12}$. Dicha autonomía del derecho es la condición que le permite plantearse de modo performativo $^{13}$. Como dice Rodríguez Velasco, a propósito de la relación entre ficción jurídica y margen, «No podemos considerar los márgenes como algo marginal. Hay un tropo que consiste en invertir la certeza sensible de que los márgenes habitan márgenes, para afirmar que éstos son en realidad el centro» ${ }^{14}$.

\footnotetext{
${ }^{9}$ «para parafrasear y resumir los argumentos centrales del autor», ibid, p. 123.

10 «los más amplios dominios de la discusión histórica y literaria o en la especulación filosófica», ibid, p. 124.

${ }^{11}$ Cf. RODRÍGUEZ VELASCO, Jesús, «La urgente presencia de Las Siete Partidas», in La Corónica, 38.2, 2010, p. $97-$ 134.

${ }^{12}$ Cf. LUHMANN, Niklas, Law as a social system, Oxford, Oxford University Press, 2004 y BOURDIEU, Pierre «La force du droit. Éléments pour une sociologie du champ juridique», in Actes de la recherche en sciences sociales, 64, 1986, p. 3-19.

${ }^{13}$ Con este término hacemos referencia a un concepto harto conocido en el mundo de la historia del derecho y que se refiere a la capacidad de ciertos enunciados de hacer efectivo un acto por medio de su expresión. Es decir que ciertas formas de enunciación, lejos de la descripción de valor verdadero o falso, producen una realidad que no se puede medir con parámetros lógicos. El registro jurídico estaría respondiendo entonces, en términos de taxonomía clásica, a la retórica más que a la lógica. Uno de los casos paradigmáticos es el de la ficción jurídica, donde se da por verdadero algo que no tiene correspondencia inmediata en la realidad pero que obtiene entidad por la utilidad de dicha «existencia» para la resolución de algún problema de ese mismo orden jurídico. Vale aclarar, como expresaba Thomas, que el derecho (por ello los juristas, de toda época) es plenamente consciente del status de la ficción en su registro discursivo, de allí que exista por su extrema necesidad y que forme parte de la pragmática del derecho (THOMAS, Yan, «Fictio legis. L'empire de la fiction romaine et ses limites médiévales», in Les opérations du droit, París, Gallimard, 2011. En referencia a los enunciados performativos cf. AUSTIN, John Langshaw, How to do Things with Words, Cambridge, MA, Harvard University Press, 1975, 1962.

${ }^{14}$ RODRÍGUEZ VELASCO, Jesús, Plebeyos Márgenes. Ficción, Industria del Derecho y Ciencia Literaria (siglos XIII-XIV), Salamanca, SEMYR, p. 14. A su vez, esta idea se puede rastrear en FOUCAULT, Michel, L'ordre du discours, Paris, Gallimard, 1971, y en COPELAND, Rita, Rethoric, Hermeneutics, and Translations in the Middle Ages: Academic Traditions and Vernacular Texts, Cambridge, MA, Cambridge University Press, 1991. Vale aclarar que este tropo resulta una simpleza. Sin embargo, como bien entiende Rodríguez Velasco, resulta una simpleza razonable. De allí que se lo haya
} 
Se podría decir entonces que la historia del libro, en sentido material y textual, se encuentra atravesada por la escritura marginal. Si esto es importante y guía el trabajo de análisis sobre comentarios literales (descripción objetiva), qué decir sobre las glosas de carácter hermenéutico. El margen es la puerta de acceso al texto, pero más importante aún será su función de satélite en la medida que cambia el sentido original de ese centro gravitatorio ${ }^{15}$. A partir de esta analogía podemos inferir el funcionamiento constante de una glosa que resignifica el texto fuente. Mientras el centro es la materia conocida, el margen, como satélite hace mutar el significado original y lo resemantiza por fuerza de la focalización. Este fenómeno es material y no solo intelectual. La glosa encierra y protege al texto, a la vez que lo destruye con ese mismo marco hermenéutico al cortar la ilación sintáctica del razonamiento para discurrir con la opinión propia que intenta imponer. Se produce una suerte de desfase de la línea de lectura con la intención de reubicar al lector en otro lado y proporcionarle como sentido último del texto que lee la interpretación del glosador ${ }^{16}$.

En rigor, Las Siete Partidas nos obliga a colocarnos de lleno en esta realidad y plantea, a su vez, al estudio de sus glosas, en especial la del apparatus de 1555, como una necesidad irreductible en el camino de establecer una historia completa de su funcionamiento. Las Siete Partidas fue «[the] Medieval Europe's greatest secular legal code»». En este contexto, desde el siglo XIII hasta nuestros días ha estado en el ojo de la tormenta de la política española, sea esta monarquía, imperio, dictadura o monarquía constitucional. Su presencia desde 1265 hasta 1985 se ha visto constantemente renovada a través de ediciones y promulgaciones (a lo que deberá sumarse su uso en el código legal vigente hasta principios del siglo XX del Estado de Luisiana ${ }^{18}$ ) las cuales, a su vez, expusieron apparati que le sumaron riqueza hasta el punto de que uno de ellos, el realizado en 1555 por el Licenciado Gregorio López, es capaz de brindarnos nuevas dimensiones que seguir estudiando este texto tan profundo.

\section{Alfonso X y Las Siete Partidas, un acercamiento al siglo XIII}

Alfonso X el Sabio (1252-84) dedicó gran parte de su reinado a dos objetivos políticos: unificación jurídica de los territorios bajo la corona castellana y consecución de la corona imperial (a esto último se lo conoce como fecho del imperio). Sobre ambos fenómenos hay certera bibliografía $^{19}$. En este sentido, no debe esperarse un análisis particularmente original en esta

usado hasta el hartazgo, incluso por el propio Rodríguez Velasco en «La Bibliotheca y los Márgenes. Ensayo teórico sobre la glosa en el ámbito cortesano del siglo XV en Castilla. I: Códice, dialéctica y autoridad», in Humanista, 1, 2001, p. $119-134$.

${ }^{15}$ El concepto de satélite, en este caso, es el propio de la semántica cognitiva. Yo lo tomo de RODRÍGUEZ VELASCO, Jesús, «La producción del margen», in La Corónica, 39, 1, 2010, p. 249-72.

16 A modo de ejemplo, en Partidas algunas de las glosas que cumplen con esta característica son: ad verbum pobres en $P$. I, V, 3; ad verbum mayor en $P$. II, XV, 2; ad verbum pariente en $P$. II, XV, 2; ad verbum fe en $P$. II, XXII, 2; ad verbum valdrá en $P$. VI, IX, 22; ad verbum vender en $P$. VI, XI, 6; ad verbum mujeres en P. VI, XIII, 3; entre otras. En promedio, cada una de ellas tiene alrededor de cuatro folios de extensión.

17 «el código jurídico secular más importante de la Europa medieval», cf. CRADDOCK, Jerry, «Must the King Obey his Laws?», in Florilegium Hispanicum: Medieval and Golden Age Studies Presented to Dorothy Clotelle Clarke, Madison, Hispanic Seminary of Medieval Studies, 1983, p. 71-79.

18 Cf. PORCEL, Julio, «Las Siete Partidas y el vigente Código Civil en el Estado norteamericano de Luisiana», in Anales de la Universidad de Murcia, 21, 1962-63, p. 187-197; BATIZA, Rodolfo, «The Louisiana Civil Code of 1808: Its Actual Sources and Present Relevance», in Tulane Law Review, 46, 1, 1971; PASCAL, Robert, "Sources of the Digest of 1808: a Reply to Professor Batiza», in Tulane Law Review, 46, 4, 1972, p. 603-627; STONE, Marylin, «Desde "Las siete partidas" a los códigos civiles norteamericanos», in Actas de XI Congreso de la Asociación Internacional de Hispanistas, 3 1994, p. 25-33.

${ }^{19}$ ESTEPA DÍEZ, Carlos, "Alfonso X y el "fecho del Imperio"», in Revista de Occidente, 43, 1984, p. 43-54, allí se encontrarán profusas referencias sobre la temática. 
sección, sino que vamos a profundizar algunos aspectos conflictivos que refieren a la propaganda político-monárquica en tiempos de tensión por la inacabada coronación del rex romanorum electo, Alfonso el Sabio. Esto nos servirá de base para lo que sigue, ya que si la intención es ver el margen como resemantizador, primero debemos entender la materia que será objeto de dicha práctica para poder comprobar que hay un giro de sentido deliberado.

El primer título de la Primera Partida se dedica a la ley y su naturaleza; luego, en el segundo, despliega un trabajo de definición en torno al uso, la costumbre y el fuero. El resto de los veintidós títulos se dedica a cuestiones de definición de los dogmas, sacramentos, artículos, y funcionamientos en general pertenecientes a la Iglesia. Cabe resaltar que el hecho de que Alfonso $\mathrm{X}$ se plantee la tarea de compilar en su código legal cuestiones que se suponen están reservadas a la esfera puramente canónica nos muestra un primer síntoma de la posición que pretenderá ocupar. Asimismo, nada de lo planteado en la Primera Partida tuvo sanción eclesiástica oficial ${ }^{20}$. Sin embargo, dejamos esto con la intención de dar paso a un estudio de carácter más textual ${ }^{21}$.

A partir del título III de la Primera Partida, Alfonso X se propone definir cuestiones centrales de dogma y eclesiología. De hecho, prácticamente toda la Primera Partida se dedica al derecho de la Iglesia en general. Vamos a comenzar por el título $\mathrm{V}$ que reviste una importancia central ya que allí definirá, entre otras cosas, al Papa. En dicha sección se encontrará, por sobre otros procedimientos, una fuerte presencia de la etimología. Como es bien conocido, Alfonso X hizo un uso extensivo de este procedimiento para la argumentación por tres vías: argumento de omnisciencia, argumento de veracidad y argumento de objetividad ${ }^{22}$. Estas tres posibilidades argumentativas, combinadas, provocan un efecto de realidad por correlación entre la interpretación verbal con la material, lo cual es fundamental en el sistema de ilación argumental alfonsí.

El proemio del título describe la función de prelatura como la de mostrar la fe y otorgar sacramentos. En las sucesivas leyes mostrará el origen del nombre obispo y prelado en general definiendo consecuentemente su lugar. Seguidamente, el texto definirá al "apostólico". Así, lo compara con los demás obispos y nuevamente vuelve a la etimología para referir al Papa, establece una escala de jerarquía y finalmente pasa a los patriarcas.

La definición sostiene que «perlado» significa «adelantado en santa eglesia». Allí, los más honrados son los obispos: «que maguer ha papa e patriarchas e arçobispos e primados [...] todos estos son obispos como quier que ayan los nomes departidos» (P. I, V, 1). Es decir que, aunque exista el Papa, los patriarcas y arzobispos, todos son obispos, iguales pero con distintos nombres. Obispo, entonces, significa «guardador» (videntes) ya que tienen el lugar de los apóstoles y, por extensión, el mismo poder que Jesucristo le dio a todo ellos: ligar y desatar en el cielo a partir de su acción homóloga en la tierra. Por esto, explica Alfonso, son los pilares de «santa eglesia». Este planteo sirve de base para lo que sigue, la explicación del lugar del Papa sobre la base de la noción de mayoría. De esta manera, la «mayoría [que] han los unos perlados sobre los otros» se expresa como una relación jerárquica basada en el orden y no en la naturaleza. Del mismo modo en que major ecclesia se usa para definir la catedral por su tamaño, en este caso la referencia indica una mayor preeminencia dentro del mismo orden con arreglo a la costumbre de seguir a uno, tal y como Cristo lo quiso al elegir a Pedro como sucesor ${ }^{23}$. Esto se comprueba cuando plantea que

${ }^{20}$ CRADDOCK, Jerry, Must the King obey, op. cit., p. 75.

21 Los trabajos más interesantes para ver estas cuestiones desde otros puntos de vista son, entre otros: CRADDOCK, Jerry, Must de king obey, op. cit.; MACDONALD, Robert, «Problemas políticos y derecho alfonsino considerados desde tres puntos de vista», in Anuario de historia del derecho español, 54, 1984; MARTIN, Georges, «Alphonse X ou la science politique. Septenaire, 1-11», in Cabiers de Linguistique Hispanique Médiévale, 18-19, 19931994; LINEHAN, Linehan, Peter, «Pseudo-historia y pseudo-liturgia en la obra alfonsina», in España y Europa, un pasado jurídico común, Murcia, 1986.

${ }^{22}$ Cf. LODARES, Juan Ramón, «El mundo en palabras. Sobre las motivaciones del escritorio alfonsí en la definición, etimología, glosa e interpretación de voces», in Cabiers de Linguistique Hispanique Médiévale, 21, p. 105-118.

${ }^{23}$ Esta idea que, naturalmente, se basa en el ya agotado y estudiado Mt. 16, 16-19, versículos que fueron centrales en los fundamentos de la llamada reforma gregoriana, se sostiene a través de diversas enseñanzas en el período bajo medieval con mucha soltura. A esto debe sumarse la observancia sobre los cánones de los concilios de Nicea I, 
Pedro tiene mayoría sobre los apóstoles (P. I, V, 2). De este modo, la idea cristiana contenida en la primacía romana es la del seguimiento de un hombre, tal como con Cristo. La noción de imitatio, que le da forma al método, sustenta en Partidas la aseveración de que el Papa es el más importante apóstol en tanto que es el «vicario de Cristo» en su diócesis.

Por esto último es por lo que recibe el nombre especial de «apostólico». Dicho nombre, que fue atribuido al Papa por el concilio de Reims en 1049 bajo el pontificado de León IX, en realidad refiere a una sucesión directa y única del apostolado ${ }^{24}$. De este modo, entraría en contradicción la noción que mueve el nombre apostolicus tal y como fue planteado en el concilio, con lo dicho previamente por Alfonso en relación a que todos los prelados son apostólicos. Dicha contradicción no será inhabitual. Todo esto se ve con mayor claridad cuando continúa en la tercera ley y reafirma que «Apostólico de Roma obispo es también como uno de los otros». Como puede verse, luego de cada argumentación por vía canónica del primado romano, Alfonso $\mathrm{X}$ inicia la próxima ley reafirmando la idea de un apostolado compartido. Prosigue con una explicación a partir de la enseñanzas de Cristo para explicar que Pedro fue adelantado por sobre el resto y por eso se convierte en cabeza, pero finaliza la presente ley explicitando que el Papa es a sus obispos lo que Pedro fue al resto de los apóstoles, su cabeza en tanto guía tras la muerte de Cristo. A partir de allí enlaza la oración consecuente con una adversativa para establecer que cada obispo tiene «logar de nuestro señor Jesucristo e sea vicario de el sobre aquellos que son dados en su obispado para aver poder de ligar e de absolver». Posteriormente establece que así como cada obispo es vicario de Cristo en su diócesis, el Papa, que es también un obispo, lo es en la suya propia, sola que esta comprende a la cristiandad toda.

Ahora pasamos al método etimológico. Alfonso el Sabio define Papa a partir de la idea de padre. Sin embargo, plantea que todos los obispos son «padres spiritualmente» ${ }^{25}$ y establece concatenadamente una estructura comparativa de dos términos encabezados por la conjunción $c a$, la cual determina un enlace causal muy fuerte ${ }^{26}$. Así como el poder sobre las cosas del mundo va hacia Dios, de donde lo recibieron, el poder que tienen los prelados en la Iglesia va y se conglomera en el Papa. La comparación se une por medio del conector frástico otrosi con la mera intención de adicionar un período sobre otro y concatenar una secuencia lógica de argumentación para establecer, en este caso, la validez por medio de la analogía de funcionamiento. Sin embargo, esta comparación implica una diferenciación por medio de la delimitación de esferas de acción. Así, por la naturaleza tanto del Papa como del resto de los prelados la incumbencia de sus acciones y poder se refiere por exclusivo a lo que comprende a la santa eglesia, mientras que hay más cosas y son las que atañen al mundo todo. La manera en la que construye el razonamiento deja ver que va de lo general a lo particular por medio de la especificación. Así, resulta innegable que en este discurso hay un planteo que hace que santa eglesia deba ser tomada bajo la idea de institución, no total, sino guardadora y defensora de la fe y los sacramentos, fundamentalmente para atar y desatar. Mientras que el resto del mundo (proclive al pecado, humano, etc.) expresa otras esferas de acción que, para entrar al mundo de los cielos deberá erogar sus acciones frente a quienes representan a quien vino a salvar a los hombres, pero no implica que esta capacidad

Calcedonia y, fundamentalmente, Constantinopla I. Es decir, estas nociones son las formal y obligadamente aceptadas en el Occidente latino continental. No es aquí, entonces, donde encontraremos formulaciones de importancia (para ver las fuentes canónicas y eclesiásticas en general de Partidas, tarea que no nos ocupa a nosotros, ver GARCÍA Y GARCÍA, Antonio, «Fuentes Canónicas de las Partidas, in Glossae. Revista de Historia del Derecho Europeo, 3, 1992.

${ }^{24}$ AZZARA, Claudio, Il papato nel Medioevo, Boloña, Il Mulino, 2006, p. 52.

25 Para entender la caracterización que Alfonso hace del espacio espiritual cf. infra sobre el prólogo a la Segunda Partida. Cf. MARTIN, Georges, «Alphonse X de Castille, Roi et Empereur. Commentaire du premier titre de la Deuxième partie», in Cabiers de linguistique hispanique médiévale, 23, 2000, p. 323-48.

${ }^{26}$ Resulta esencial el trabajo de LACOMBA, Marta, «Un discours historique marqué par la causalité: l'utilisation de la conjonction ca dans l'Estoria de España d'Alphonse X», in Cabiers de linguistique hispanique meédiévale, 27, 2004, p. 71-82 para entender la importancia profunda de estas maneras de construir el relato en la obra alfonsí. 
conlleve poder sobre cuestiones no referidas al ámbito del pecado individual, a lo escondido ${ }^{27}$. La función entonces del Papa será la de ser «mantenedor de la fe» (P. I, V, 4).

Seguirá el resto de las leyes dedicadas al Papa con delimitación constante de la esfera de acción. En la ley V establecerá que el Papa puede llamar a los príncipes de la tierra para el tratamiento de cuestiones de la fe o para su acrecentamiento. Asimismo, dice que el Papa puede hacer establecimientos y decretos referidos a la Iglesia y para mejora de la cristiandad, pero solo en cuestiones espirituales y lo deben guardar los cristianos. Este último punto resulta muy sugerente, ya que la definición de ley, elemento jurídico que aquí no le atribuye al Papa, implica una obediencia absoluta sin mediar como justificación de no observancia ni «creencia, ni linage, ni poder, ni honrra, ni aun por demostrarse por vil en su vida o en sus fechos [...]. [En definitiva], ninguno no puede ser escusado de las non obedecer e las guardar $[\ldots]$, naturales o moradores» $(P$. I, I, 16). En este caso, esta diferencia está mostrando esferas de acción separadas por medio del alcance y del objetivo de las mismas.

En la ley VII vuelve a plantear un espacio de acción consecuente con el discurso aquí estudiado y establece, frente a la elección papal, que en caso de producirse un cambio en el sistema a través de los medios legales pertinentes los cristianos deben aceptarlo, «ca este fecho le pertenece solamente porque es spirituali. $\mathrm{Y}$ es decir que el Papa se arroga el derecho de cambiar cualquier cosa por los medios legales pertinentes que pertenezcan a la Iglesia y los cristianos, y solamente ellos, lo deben observar. Finalmente, la ley VIII establece que los cristianos deben respetar y amar al Papa pues es vicario de Cristo y por extensión recibe el amor que le deben al primero. Una vez más, circunscribe su ámbito de acción y poder a los cristianos para cuestiones que atañen a lo espiritual, lo cual, como ya vimos, no es todo lo que conforma la realidad.

La Segunda Partida es un tratado de derecho político, es decir que aglutina una serie de explicaciones sobre fenómenos referentes a la propia teoría del Estado y las formas de gobierno. Allí se expone la organización del poder regio como también la estructura y funcionamiento de la sociedad. Este texto comporta una riqueza infranqueable en lo que al proyecto imperial alfonsí refirió, como así también en lo que concierne a la monarquía y, desde una perspectiva más general, resulta un hito insoslayable para la historia del tratadismo político cristiano de los siglos XIII y XIV. En definitiva, en ese libro se encuentra la mayor parte de la teoría política alfonsí, ya que en la Primera Partida se exponen regulaciones en torno a la ley, habitual temática de la codificación civil en la modernidad y, en algún punto, por esto mismo, perteneciente al Derecho constitucional, el cual es, en última instancia, parte del Derecho político. Sin embargo, como vimos, el grueso del primer libro lo constituye el derecho eclesiástico. Creemos que el orden de exposición responde a otros principios del clásico «Dios es comienço, e medio e acabamiento de todas las cosas» ( $P$. I, prólogo). Sin embargo, sin negar esta proposición, debemos argumentar en torno a una lógica temporal e histórica del discurso alfonsí. En este sentido, el primer libro (salvo los dos primeros títulos) responde a la propia acción legitimadora del código general de regular todo aquello que atañe a la vida social, incluso aquello que corresponde a otra esfera: la canónica. Esta aparente confusión de esferas se hace, paradójicamente, con la intención constante de delimitarlas. Así, la regulación eclesiástica queda referida entre la temática central de la compilación: hacer la ley (tarea solo reservada a reyes y emperadores) P. I, I y II, y el libro dedicado por entero al Derecho político encarnado en esos mismos reyes y emperadores. En este sentido, Dios (en el discurso alfonsí, en clara lógica con una antropología cristiana medieval) es hacedor de todo, pero la esfera temporal es, separadamente de la espiritual, parte central y, de hecho, aquella que sirve para penar los males contra la fe. Por ello, la verdadera razón del orden no se expone donde Martín señala, sino mucho más adelante cuando Alfonso plantea que:

\footnotetext{
${ }^{27}$ Cf. MORIN, Alejandro, Pecado y Delito en la Edad Media. Estudio de una relación a partir de la obra jurídica de Alfonso el Sabio, Córdoba, Del Copista, 2009. Allí se pueden encontrar información y profusa referencia sobre los principios y contradicciones de la separación de jurisdicciones sobre la base de lo oculto y lo evidente en relación a las acciones jurídica y canónica (pero no expresa en absoluto esta lectura nuestra).
} 
[...], han de guardar la fe, non tan solamente de los enemigos manifiestos que en ella no creen, mas aun de los malos cristianos atrevidos que la non obedecen ni la quieren tener nin guardar e por que esto es cosa que se deve vedar e escarmentar crudamente lo que ellos non pueden fazer por ser el su poderio espiritual que es todolleno de piedad e de merced. Por ende, nuestro señor Dios puso otro poder temporal en la tierra con que esto se compliese ${ }^{28}$.

De este modo, lo que ocurre es que es el poder laico es el que está en primer plano como protector de aquello que el eclesiástico muestra y conoce, pero que solo el primero puede hacer perdurar por medio del castigo de aquellos que dentro de la fe cristiana no la obedecen: enemigos internos. Por esto, el problema es temporal, pues la fe de Jesucristo está primero, pero insostenible por sí misma y constantemente atentada por la naturaleza humana, Dios coloca otro poder para que se cumpla verdaderamente. Partidas respeta y entiende la obra divina pero a partir de una sola visión: la del poder laico. Esta imagen forma la visión sobre la teoría de las dos espadas que Alfonso expone en esta Partida.

El hincapié principal está en sostener que la Iglesia es la detentadora de un poder didáctico, de verdadero conocimiento y, si se quiere, prescriptivo. Sin embargo, su existencia (real y metafórica) se asienta sobre la primera venida de Cristo, naturalmente. Así, es él quien, a través de sus enseñanzas, siembra algo en la tierra que debe perdurar pues es querido por Dios. Sin embargo, este nuevo tiempo no implica la supresión absoluta del anterior. En la sexta ley del título I de la Segunda Partida Alfonso explica de dónde salen los reyes. Por medio de la referencia ad auctoritatem de Aristóteles (una de las pocas fuentes directas citadas en Siete Partidas) muestra que previo a la encarnación del Espíritu Santo los reyes concentraban en sí las funciones temporal y espiritual. Si bien el contexto no es grato para un cristiano, pues el fin de los gentiles se da por medio de la verdad revelada, debemos entender dos situaciones que hacen que la inclusión de esta información no sea de consideración menor para los redactores de Partidas. En primer lugar, la idea de la definición lexicográfica por vía no solo etimológica implica, en el modelo de pensamiento y trabajo alfonsí una máxima que no derrocha energías sin conseguir alguna utilidad, cuando menos, de eficacia retórica ${ }^{29}$. De esta manera, la existencia de este uso no es menor, pues se mantiene. Concatenadamente a esto aparece la segunda situación. Por medio de la parataxis Alfonso lleva esta explicación al plano de la verdad sosteniendo que rey es como Dios, quien contiene tanto el poder temporal como espiritual en uno solo. Asimismo, resalta su lugar político en tanto que es «rey sobre todos los reyes, porque del han nome, e los gobierna e los mantiene en su lugar en la tierra para fazer justicia e derecho». La construcción comienza por el anuncio del tradicional método «científico» del rey Sabio. En este discurso, el título de la ley prepara al lector para la explicación que va a venir. Seguidamente, establece un origen históricamente explicado del término rey, el cual implicaba en ese origen la unión de poderes ${ }^{30}$. Si bien esta opción no es la sostenida por Alfonso X, la forma de argumentación por medio de la lexicografía y la digresión descansa en dar cierta preeminencia al rey en un contexto de conflicto.

\footnotetext{
${ }^{28}$ Las Siete Partidas, op. cit., (P. II, proemio).

${ }^{29}$ VAN SCOY, Herbert, «Alfonso X as a lexicographer», in Hispanic review, 8.4, 1940 ; «Alfonso X. educator», in South Atlantic Bulletin, 24.1, 1958.

30 Todo esto tiene dos correlatos en el mundo oriental que son fundamentales. En primer lugar, la propia cita a Aristóteles muestra la recepción no solo de la política sino también de la ética. Esto abre la puerta a pensar que por las tradicionales, en el taller alfonsí, vías judeo-árabes de la tradición política griego-oriental algo más pudo haber entrado. En segundo lugar, esta noción cesaropapista que no se plasma en Occidente, al menos hasta el Leviatán, muestra lecturas bizantinas, principalmente Eusebio de Cesarea. Cf. FERREIRO ALEMPARTE, Jaime, «Recepción de las Éticas y de la Política de Aristóteles en las Siete Partidas del Rey Sabio», in Glossae, 1, 1988; MARTIN, Georges, Alphonse X, op. cit:; BuRns, J. H., Medieval Political Thought, c. 350-c. 1450, Cambridge, Cambridge University Press, 1988 y DAGRON, Gilbert, Empereur et prêtre: étude sur le césaropapisme byzantin, París, Gallimard, 1996. Las relaciones concretas de Alfonso X con Bizancio siguen siendo un tema virtualmente inexplorado. Tenemos la segura conexión como ya señaló LINEHAN, Peter, Pseudo historia, op. cit., p. 263, pero poco más.
} 
La necesidad de ocupar tal cantidad de leyes en sostener que ambas espadas son «departimientos» de un poder concentrado previamente, sumado a resaltar la igualdad de importancia para el mantenimiento del mundo muestra una necesidad y vemos en esa necesidad un conflicto.

Sigue a esta argumentación el complemento histórico. Luego de presentar el origen divino de la institución, debe explicar por qué existe, entonces, la Iglesia. Así, sostiene que la llegada históricamente datada de Dios se dio por medio de Cristo, otra e igual persona, su hijo. Así, previo al momento de revelarse totalmente por medio de la resurrección, en la última cena explicó que de allí en más serían dos las espadas que cuidarían la verdad, ayuntadas para dar justicia al alma y al cuerpo ${ }^{31}$.

El Occidente cristiano medieval continental asiste en el siglo XIII a varios procesos muy complejos y que le dan forma a la baja Edad Media y, a su vez, catapultan una serie de elementos que caracterizarán el mundo político, jurídico e ideológico de la temprana modernidad. Ninguno de estos fenómenos es preeminente sobre el resto sino que confluyen dentro de un proceso de larga duración relacionado con la consolidación de monarquías nacionales. Si como dijo Le Goff dicho siglo es el del apogeo del cristianismo, también es el siglo de la obsesión por el archivo, por la copia y la profesionalización y la laicización de todo en vía de reemplazar los cuerpos reales por los documentales ${ }^{32}$. Esta nueva forma de dominación por vía del Derecho tiene como correlato dos procesos más: la centralización monárquica (en contante y evidente relación con las herramientas jurídicas) y la desacreditación de la institución imperial. En este contexto, pareciera que la intención de Alfonso X por lograr su elección por vía de la materna sucessio a la cátedra germánica no tendría sentido. Sin embargo, la tarea política llevada a cabo por el rey Sabio consistió en buscar (y cuando no crear) el acrecentamiento de su influencia y eficacia política por medio de la concentración de poder simbólico. Esto no se relaciona solamente con un lugar de prestigio sino también con la necesidad de hacer más efectivas sus políticas.

Como bien plantea Núñez Rodríguez ${ }^{33}$, Alfonso puso grandes esfuerzos en conseguir esta dimensión universalista de poder por medio de la conjuración de ese pasado glorioso que sustenta la base de construcción ideológica de la unificación nacional monárquica. Esto se produce sin escamotear la evidencia de la limitada capacidad de decisión y efectividad que el imperio tenía. Sin embargo, lo que en el plano concreto carece de fuerza, en el plano simbólico guarda su empuje inicial. Interesante es ver que esta lógica de acumulación simbólica recaía con tremendas consecuencias sobre la población castellana, particularmente sobre sus «bolsillos» ${ }^{34}$.

Más allá de esto, Siete Partidas muestra sintomáticamente esta circunstancia. En ese sentido, vamos a mostrar la manera en la que Alfonso X planteó ambas instituciones.

La presentación en el proemio del título I de la Segunda Partida muestra el tradicional respeto por la tradición heredada. Sin embargo, desde el principio coloca en un plano de semejanza la «honrra» de ambas instituciones. Así, «Emperadores e reyes son los mas nobles omes [...]». Prosigue sosteniendo que Dios coloca al rey en la tierra y también al emperador, pero este último por medio del «otorgamiento que le fizieron las gentes». Esta distinción resulta de peso para el sistema de legitimación ideológica bajo medieval, ya que en este período comienza a formularse explícitamente la teoría descendente del monarca. Esto obedece a un clima donde lo

\footnotetext{
${ }^{31}$ Las Siete Partidas, op. cit., (P. II, proemio).

${ }^{32}$ LE GOFF, Jacques, Le XIII siècle: L’apogée de la chrétienté, París, Bordas, 1992 y RODRÍGUEZ VELASCO, Jesús, «Diabólicos quirógrafos, o cómo creer la piel de un animal muerto», in El Cronista, 40, 2013, p. 38.

${ }^{33}$ NÚÑEZ RODRÍGUEZ, Manuel, «El rey, la catedral y la expresión de un programa», in Espacio, tiempo y forma, VII, 1992, p. 27-52 y «Non avemos mayor sobre nos en lo temporal: Alfonso X y la imagen de autoridad», in Temas Medievales, 3 , 1993, p. 29-46.

34 Sobre la cuestión del gasto y la ruina económica por los gastos en el fecho del imperio corrieron ríos de tinta, no vamos a contribuir ya que, además, excede nuestro tema. La bibliografía esencial es ESTEPA DÍEZ, Carlos, «Alfonso X y el 'fecho del Imperio'», in Revista de Occidente, 43, 1984, p. 43-54, y RODRÍGUEZ LÓPEZ, Ana, «Rico fincas de tierra et de muchos buenos vasallos, mas que rey que en la cristiandat ssea. La herencia regia de Alfonso X», Cabiers de linguistique bispanique médiévale, 23, 2000, p. 243-61, entre otros. En estos trabajos se podrá encontrar profusas referencias a todo lo necesario.
} 
sobrenatural comienza a funcionar como medio de legitimación del poder temporal sin intermediación, cosa que no consiguen con facilidad los publicistas imperiales por los problemas de elección y coronación. Si bien estos elementos son constantemente revisados, la necesidad de la «solución papal» para establecer una legitimidad perdurable es sine qua non. El ejemplo más claro está constituido por los conflictos militares que fueron necesarios, más allá de comportar absoluta claridad la elección, para que Clemente VII coronara a Carlos V en 1527. En rigor, los elementos rituales relacionados con la unción que Alfonso X se preocupa por mostrar tienen una significación particular (cuando Castilla no acostumbraba la coronación, excepto casos raros, como Alfonso VII, imperator in regno suo, ni que hablar de coronación al inicio del reinado, que no se producía desde Alfonso VI en 1077 y que recién quebró su «hijo maldito» Sancho IV en $1284)^{35}$. Sin embargo, su caracterización debe corresponder, en lo referido a la separación de esferas, con la lógica laicicista. Por lo tanto, su raíl hacia el vértice del poder simbólico se mantiene intacto. En rigor, sostiene que el emperador no debe obedecer a nadie en lo temporal. Sin embargo, muestra la lógica de centralización monárquica planteando, en contradicción con lo que dirá Bartolo de Sassoferrato, que el emperador solo manda dentro de los límites de su imperio. Poco tiempo después, el jurista italiano, en claro ejercicio de reafirmar lo que la publicística imperial sostenía desde antaño, va a decir que «imperator est dominus totius orbis, quod verum est de iure licet de facto non obediant ${ }^{36}$ (Bartolus de Saxoferrato, Index...) de igual modo que la glosa ordinaria ad verbum «minime recognoscat» del $X 4,17,3$. Estos son solo algunos ejemplos del período de los posglosadores. Sin embargo, desde el siglo XV será prácticamente imposible de sostener. Como muestra la glosa de Díaz de Montalvo (1492) en la reproducción de $1542^{37}$ donde sutilmente indica en la glosa ad verbum «todos» que «erat dominus totius mundi $[\ldots]\rangle^{38}$.

El emperador debe ser uno. Esto se explica por cuatro razones: la primera, que pueda quebrantar los desacuerdos de la multitud para llevarlos a la unidad. Este principio solo sería alcanzable por medio de la unidad de origen para la resolución de los conflictos inherentes de la vida social multiplicada. Segunda, para poder hacer leyes y fueros. Sostiene así la monogénesis de la factura de la ley. Este planteo de cuño justinianeo se basa en la posibilidad o no de que la autoridad monárquica o imperial esté sujeta a esas mismas leyes. La relación es muy clara. La exclusión de la posibilidad de hacer leyes y fueros, que en el discurso alfonsí es lo que comprende por entero al Derecho, implica que el «fazedor» es fuente del Derecho mismo. Por lo tanto, la ley y el dador de ella son uno ${ }^{39}$. Tercera, para «quebrantar a los sobervios [...]». Cuarta, para proteger la fe cristiana y quebrantar a sus enemigos. Seguidamente, sostiene que el emperador es vicario de

\footnotetext{
${ }^{35} \mathrm{Al}$ respecto, todo el texto de LINEHAN, Peter, Pseudo-bistoria, op. cit., proporciona datos sobre la coronación y la unción en la España medieval. Vale aclarar que sería interesante incluir el fenómeno de la auto investidura caballeresca, acto que realiza Alfonso X, entre otros, pero que por necesidad metodológica dejamos de lado. MARTIN, Georges, «Control regio de la violencia nobiliaria. La caballería según Alfonso X de Castilla (comentario al título XXI de la Segunda Partida)", in Cahiers de linguistique hispanique médiévale, anexo 16, 2004 y RODRÍGUEZ VELASCO, Jesús, Ciudadanía, soberanía monárquica y caballería. Poética del orden de caballería. Madrid, AKAL, 2009, entre muchos otros, proveen la información necesaria incluyendo profusas referencias a la tradición historiográfica del tema y verdaderamente lo agotan en gran modo.

36 «El emperador es señor de todo el mundo, lo cual es cierto por derecho, aunque de hecho no lo obedezcan».

${ }^{37}$ La edición original es de 1491 pero carece de glosa, la cual fue terminada poco después en 1492 y comienza a aparecer en reproducciones posteriores.

38 «[el emperador] era señor sobre todo el mundo». Las negritas son nuestras.

${ }^{39} \mathrm{La}$ idea es la de una ley que se antropomorfiza por medio de la sobreposición de la imago regis con la imago legis. Esto es complejo y excede el espacio previsto, lo desarrollamos de manera completa en nuestro trabajo doctoral. Esta noción, a su vez, posee un anclaje en el CIC ya que conlleva la idea, para la tercera redacción de Partidas, del clásico rex legibus solutus est. En referencia a la idea de redacciones sucesivas y sus cambios, la información se encuentra en CRADDOCK, Jerry, Must the king, op. cit. El autor propone la hipótesis de tres redacciones sucesivas de Partidas que responden a los distintos momentos políticos que vivía el rey Sabio. Así, cada una de esas redacciones muestra instancias de conflicto distintas y, en referencia a lo que planteamos aquí, una suerte de radicalización de los elementos que marcan superioridad monárquica.
} 
Dios para hacer justicia en lo temporal, así como el papa lo es en lo espiritual. Esto nos permite centrar momentáneamente el análisis en algunas cuestiones de uso y lenguaje.

Alfonso X plantea una serie de diferencias entre ambas instituciones. A pesar de considerar que «emperadores e reyes son los mas nobles omes e personas e honrra e en poder que todas las otras [...], E porque ellos son asi como començamiento e cabeça de los otros, queremos primero fablar de ellos», veremos cómo se puede percibir un síntoma del descrédito de la institución imperial frente a la monárquica ${ }^{40}$. Para hacer más amena esta exposición solo vamos a considerar cuatro puntos expuestos en la Segunda Partida que reflejan esta diferenciación mencionada. En la ley séptima del primer título, expone que:

Complidas e verdaderas razones mostraron los sabios antiguos porque convino que fuese rey, mas de aquellas que de suso diximos del emperador. E como quier que ante fablamos del por la honrra del imperio que del rey, pero antiguamente primero fueron los reyes que los emperadores.

Este párrafo introductorio tiene dos elementos de ilación. El primero, «mas de». Dicho coordinante es aditivo. Puede verse que el planteo implica que aquello que es establecido como cierto (previo recurso habitual de autoridad a la figura «sabios antiguos») le corresponde un ensanchamiento de capacidades. La trabazón se completa sí con el coordinante adversativo «pero». Así, la preparación es la de adicionar matizando, en este caso, con un rasgo de consecuencia que se encuentra en el coordinante «demas» que es la forma, con toda seguridad, utilizada por el discurso alfonsí en esta parte (algo que puede comprobarse por las diferencias con otros mss., por ejemplo Esc. $2^{\circ}, 103 v$. c. 1), para llevar la adversativa al plano de la contraposición y no de la justificación (que habitualmente responde a «ca»). En rigor, la acumulación de relativas consiste no en la incorporación de elementos nuevos, sino en la de aquellos ya contenidos en uno catafórico previo. El objeto del discurso, en este caso, es el de argumentar por la primacía de la existencia cronológica previa. Por tanto, la vetustez de la institución es argumento de primacía.

Un segundo elemento podemos encontrarlo en la misma ley hacia el final. Este es un rasgo habitual en la construcción del párrafo alfonsí. La última oración reafirma lo expuesto introduciendo (sea por adición o consecuencia, nunca de modo adversativo) un nuevo elemento que será tratado en la ley siguiente. Así, la ilación es trabada a lo largo de todo el texto. El «aun» sirve como focalizador que parte de serie de elementos oracionales a serie de predicados por medio de la secuencialidad y de allí a períodos. Así, este uso permite registrar una gradación previa que se intensifica. Implica un escalón más que cambia cualitativamente el valor de la relación entre los elementos (y de cada uno aislado) de la operación retórica. Añade extrañeza y relevancia. Sin embargo, no es necesario que la secuencia que encabeza «aun» cierre enumeración. De esa gradación proviene la secuencia con que la oración encabezada por «aun» propone el intensivo «mas». El formato es, entonces, «A todo esto hay que sumarle esto otro (que merece ser focalizado y distinguido por su excepcionalidad)». La oración es: «E aun de mas que el rey lo tiene por heredamiento, e el emperador por eleccion». El componente previo es la capacidad de ejercer poder en el territorio competente. Así, vuelve a plantear la constante catafórica de «aquello que puede el emperador lo puede el rey» (como ya expusimos más arriba) y le suma el segundo elemento de distinción, el derecho sobre el que se origina el poder: la herencia.

El tercer elemento implica la posibilidad del uso cuasi a voluntad del territorio y todo lo que lo comprende por parte del rey, cosa que no parece tan sencilla para el emperador, según la

40 Todo lo que vamos a tratar aquí, temáticamente, debe ser resuelto tal y como lo hizo WOLF, Armin, «Derecho electivo y sucesión hereditaria en los reinos y el imperio de Alfonso el Sabio», España y Europa, un pasado jurídico común, 1986, p. 223-58. Allí, consideramos, el autor resuelve muy bien la concepción de Alfonso X sobre el tema. Explica entonces que no hay diferencia sustancial entre las formas de acceso al trono (elección o sucesión hereditaria), sino que lo hereditario es una forma determinada de elección y que la elección es una forma especial de herencia, etc. Sin embargo, nuestro trabajo está en entender cómo utiliza retóricamente esta diferencia a su favor, no como funcionaba efectivamente. 
ley VIII de este primer título de la Segunda Partida. Comienza esta ley con una apelación particular para Partidas: «Sabida cosa es...». Esta forma de conocimiento, que resulta válida en términos jurídicos para las instancias procesales de la época, y posteriores, no es frecuentemente utilizada por Alfonso X, ya que resulta más típica la invocatio a elementos concretos de sabiduría excluyentes. Sin embargo, consideramos que esta apelación implica una disminución del impacto que le permite matizar la ancha distancia que traza con la institución imperial. En este punto vuelve sobre el uso, una vez más, de la referencia catafórica previa para adicionar, por la misma vía, y con el mismo conector del primer caso, elementos de diferenciación. La construcción es sutil, pues engarza este razonamiento con el anterior por medio del «demas» que implica un matiz de consecuencia. Este uso es típico del discurso alfonsí. Suma información por medio de la parataxis y la acumulación de relativas. La manera concreta es la siguiente: dado el último elemento de la ley anterior, se desprenden todas estas cosas como consecuencia de este estado descripto. Así, al heredamiento del reino, como forma superior de origen del ejercicio del poder, se le suman todas las bondades que se desprenden necesariamente de allí: «el rey puede dar villa», «el rey puede dar castillo», «el rey se puede servir e ayudar de las gentes del reyno», etc.

El cuarto elemento se encuentra dentro del listado, pero genera tal focalización que merece estar aparte. Cuando propone esta larga lista de cosas que el rey puede hacer y el emperador no, la ley parece centrar la atención en la cuestión fiscal. De este modo, utiliza la partícula «ca», la cual implica consecuencia lógica por subordinación. Sin embargo, en este caso inicia una negación. La fórmula que prosigue es la siguiente. Para cada elemento del listado que a priori el lector sabe que responde a las facultades exclusivas del rey, le sigue la negación de que el emperador pueda hacerlo. El peso de la parataxis es notable. Asimismo, al llegar al momento de sostener que el rey puede aumentar a voluntad los impuestos, coloca la conjunción ca, la cual, según los estudios de Lacomba, es utilizada para condensar lo esencial de los diferentes hipotextos con el fin de construir un hipertexto encadenado por una gran vía causal ${ }^{41}$. De este modo, lo que plantea es que la conjunción $c a$ va a implicar elementos oracionales entre sí de modo causal de manera encadenada con el soporte constante de la parataxis para sustituir enunciados finales con enunciados causales. Este procedimiento genera una focalización por vía de la explicitación del razonamiento y exaltación de la razón de lo dicho al principio, en este caso, de la ley. Es una acumulación de elementos que se subordinan a la estructura consecutiva final para resaltar la opinión expresada.

Estos elementos fueron seleccionados en virtud de lo claro con que son expuestos. El método de análisis no se concentra en el contenido, el cual es por momentos trillado o contradictorio, otras veces inocente. La intención es mostrar cómo, en los momentos en los que la semántica no muestra mucha innovación, también se hace presente un modelo de escritura que conlleva como principio de autoridad el razonamiento encadenado para la efectividad del discurso.

A lo largo del resto de la Partida II podemos encontrar muchos casos similares a estos y agregando elogios a la monarquía, etc. El objetivo de estos últimos subapartados fue mostrar todos los ángulos diversos desde los cuales Partidas monta un aparato de funcionamiento que obedece a formas y leyes específicas y que no se agotan en el mero mensaje más o menos de pasquín. Finalmente, cabe remarcar que hay dos niveles en este texto. Por un lado, la exaltación de la figura imperial por dos vías. La primera, su contraposición al papado en tanto que, como cualquier otro poder temporal, solo debe cuentas de un modo directo a Dios, que es el fundamento de su existencia (en el caso de la elección imperial esto toma otro cariz). Segundo, por medio de la atestiguación histórica de la existencia institucional. Este afán, repetidamente buscado por medio de las obras historiográficas también, encuentra eco en las necesidades argumentales de Alfonso. El otro nivel es el que está constituido por el matiz expuesto entre el

${ }^{41}$ LACOMBA, Marta, «Un discours historique marqué par la causalité: l'utilisation de la conjonction ca dans l'Estoria de España d'Alphonse X», Cabiers de linguistique hispanique médiévale, 27, 2004, p. 71-82. 
imperio y la monarquía. Al igual que lo hace en la Primera Partida, aquí nuevamente subvierte los objetivos expuestos por los condicionamientos ideológicos del gran objetivo detrás del proceso compilatorio. Por esto, tal y como planteamos al principio el ordenamiento se regla hacia el objetivo de acumular poder simbólico, el cual no solo obedece a necesidades narrativas de creación de imaginería para librar el combate en el plano meramente discursivo. La intención de plantar ideología (no debemos olvidar que la idea era que este texto funcionase como derecho supletorio, legible y aplicable en cortes y juzgados) para generar una mejora en la capacidad concreta de ejercicio del poder. El proceso es, tal y como sostenemos desde un principio, aquel que obedece a una dialéctica del orden. Primero, plantea una fotografía de la sociedad, la cual es la mayoritariamente aceptada; segundo, pone en marcha esa imagen por medio de una ilación sutil y elaborada a efectos de conseguir establecer series consecutivas que vayan llevando al lector indefectiblemente por donde el texto lo desea. En tercer lugar, enfrenta al lector a la posición última por vía de la consecuencia, generando así un efecto de verdad inapelable y que contradice el orden tradicional que aquella ya olvidada fotografía mostraba.

\section{Gregorio López y Las Siete Partidas, un acercamiento del siglo XVI}

Gregorio López, llamado el Accursio español, fue un jurista muy importante de su época y estuvo a cargo de la edición hasta ahora más completa y erudita de Las Siete Partidas. Su glosa completa las remisiones del texto, que los redactores originales obviaron. Nacido en Guadalupe en 1496, fue humanista, jurista y abogado; miembro del Consejo de Indias, gobernador de los estados del Duque de Béjar, fiscal del Consejo de Castilla y abogado de la Real Chancillería de Granada. Sin embargo, se conoce poco y nada sobre su vida ${ }^{42}$. La fecha de 1555 no es azarosa. El proyecto carolino llegó a su fin, agotado por sus propios medios (la guerra principalmente) y derrotado dejando atrás los años de victoria, nada parecía salirle bien ya al viejo emperador. Juana de Austria, regente en España, signataria de los tres privilegios que autorizan la obra y su edición con glosa manda componer una nueva edición de Partidas. Una vez más, la crisis motiva el resurgimiento del texto. Desde 1554 Carlos se encontraba fuera de España en compañía de su hijo Felipe realizando un ceremonial penoso, aquél que lo marca como incapaz de continuar con aquello que venía realizando hacía cincuenta años: reinar. Así, en cada ciudad cabecera Carlos, vistiendo de negro (como muestran sus cronistas) realiza las abdicaciones necesarias de a una: los territorios italianos, Países Bajos, Castilla, Aragón, etc. En 1556 ya no queda nada que abdicar y Carlos se retira alejado de todo aquello en lo que creció. En este contexto se solicita Partidas. En él se podrá ubicar esta edición tan peculiar e interesante. Como ya establecimos más arriba, nuestra mirada estará en algunos de los cientos de ejemplos en los que el glosador se dedica a contraponer la pluma de Alfonso X. Queriendo quizá moldear un presente distinto de éste tan sombrío pensando ya en el porvenir del nuevo rey que deberá afrontar, prácticamente, la reconstrucción de una imagen y de un poder menguado por el paso del tiempo y las decisiones infortunadas.

Teniendo en mente lo expuesto en el apartado anterior, nos dedicaremos a mostrar la contraposición en cada glosa seleccionada para volver sobre el final con una reflexión sobre el proceder del editor de 1555.

En la glosa ad verbum «papa» (P. I, V, 4) Gregorio López va a plantear una defensa del lugar del Papa, dignidad que proviene de los tiempos de Justiniano: «Tempus antiquo istud nomen commune fuit omnibus episcopis, [...], eximium tamen fuit et quasi propium Romanorum, etiam

\footnotetext{
${ }^{42}$ RUMEU DE ARMAS, Antonio, «El jurista Gregorio López, Alcalde Mayor de Guadalupe, Consejero de Indias y Editor de Las Partidas, in Anuario de Historia del derecho español, 63-64, 1993-94, p. 345-450.
} 
Iustiniania etate qui Romanum solum Papam apellat» ${ }^{43}$. Con la introducción de este comentario ${ }^{44}$, Gregorio dejaría ver un intento de darle una primacía más marcada en medio de la homogeneización a ultranza entre obispos y Papa que realiza Alfonso. El modo simula algunas de las condiciones que Alfonso X explota en sus argumentaciones. Así, frente al razonamiento basado en la etimología y la tradición del uso, López contrapone la misma idea, disminuye el impacto del origen del uso y agrega que desde hace mucho tiempo el Papa es el obispo romano. Frente al intento de homogeneidad entre obispos, el comentador refuerza la idea del primado. En la glosa siguiente, ad verbum griego, dicha defensa se hace más evidente: «Est ergo istud verbum Papa nomen graecum quae si pater patrum [...] Papa est praecipuus Cesar alibi dicit quod est omnia et super omnia [...] Papa non est sicut homines terreni et dicitur Princeps regum terrae» ${ }^{45}$. Este pasaje tiene implicaciones más profundas. Por un lado, al afirmar la idea de un todo (que podemos suponer se refiere a lo espiritual) le da al pontífice una distinción por sobre el otro poder, el temporal. Este razonamiento es contrario a lo que plantea Alfonso en tanto que ambos poderes (temporal y espiritual) provienen de Dios, son separados y otorgados para engrandecer la cristiandad. De este modo, la intención que se explaya es la de una absorción de lo temporal por lo espiritual, lo cual se completa refiriendo que el Papa es príncipe de los reyes de la tierra. Esta capacidad de Roma de ser cabeza en todas las dimensiones, deja en un lugar complejo la guerra que tuvo lugar entre Carlos V y Clemente VII en 1527, ya que sería entonces inseparable la potestad que ejerce el Papa en lo espiritual de lo temporal. Aun aceptando la idea de que en lo político es un príncipe terrenal más y en tanto por ello se da el conflicto, la idea de príncipe de príncipes hace ver a dicho acontecimiento bélico como, por lo menos, una sublevación y no una posible guerra entre iguales jerarquías. Así, en la glosa subsiguiente ad verbum «Honrrado», advierte que la «Reuerentia quesit Papae quae sit ipsi Deo» ${ }^{46}$. La fórmula entonces se completa con el pedido de pleitesía de carácter divino para el Papa.

En la glosa ad verbum «espirituales» (P. I, V, 5), parecería dar a entender cierta capacidad del Papa de rebasar la esfera espiritual y llegar a la temporal: «Et idem videtur si disponeret circa temporalia, quando sine eis non possent ita bene ordinari spiritualia» ${ }^{47}$. Como vimos en el apartado anterior, una de las máximas de Alfonso el Sabio es circunscribir la acción del Papa al ámbito puramente espiritual. Sin embargo, con Tomás de Aquino como principal fuente, López hace notar que en caso de necesitarlo, el Papa podría intervenir en lo temporal a efectos de conseguir una mejor regulación de lo espiritual. Esta idea de excepción, en realidad, posee un peso muy fuerte en la argumentación ya que otorga al Papa, una vez más, un poder superlativo en nombre de lo espiritual que, una vez más, subsume a lo temporal.

En lo referido a la elección de los obispos, Alfonso, a través de $P$. I, V, 18, expone que:

Antigua costumbre fue de Espanna, e duro todavia, e dura oy dia, que quando fina el obispo de algun lugar, que los fazen saber el Dean e los Canonigos al Rey [...] como es finado su perlado, e que le piden por merced, que le plega que ellos puedan fazer su eleccion desembargadamente, e que le encomiendan los bienes de la Eglesia, e el Rey deue gelo otorgar, e embiar los recabdar, e despues que la eleccion ouiere fecho, presenten le el elegido, e el mande entregar aquello que rescibio.

\footnotetext{
43 «Antiguamente, este nombre fue común a todos los obispos, sin embargo, fue exclusivo y propio de los romanos, también en época de Justiniano que llamaba Papa solo al de Roma».

${ }^{44}$ En el estudio usaremos «glosa» y «comentario» como sinónimos de manera acrítica. Esto se debe a que no es un interrogante válido, para este trabajo, las diferencias estilística y temporal que implican. Al respecto puede verse DI CAMILLO, Ottavio, El humanismo castellano del siglo XV, Valencia, Fernando Torres, 1976.

45 «Entonces, la palabra papa es un nombre griego que significa padre de padres, [...], el papa es por principio césar y también todo y está sobre todos [en referencia a la alegación de Baldo]. El papa no es como el resto de los hombres terrenales y se le dice príncipe de los reyes temporales».

46 «El tratamiento que se le da al papa es el mismo que a Dios».

47 [En referencia a la capacidad de hacer establecimientos en lo espiritual]: «Lo mismo podría verse si dispusiera sobre cuestiones temporales, cuando sin ellas no se pudiera ordenar correctamente las espirituales».
} 
Sin embargo, Gregorio López, en la glosa ad verbum «costumbre», niega rotundamente esta afirmación de Alfonso $\mathrm{X}^{48}$. Allí, López mostrará que existe esa costumbre, pero la recoloca en otro sitio. Expondrá que su origen se debe al patronazgo general de los reyes de España sobre las catedrales, pero pondrá esto en un lugar anexo para sostener que la injerencia de los reyes en la elección es puramente honorífica y protocolar pero no vinculante, ni antes de establecerse ni después de realizada. Dicho reclamo de independencia es muy fuerte, mucho más en el contexto del código alfonsí, ya que el rey Sabio fue un asiduo manipulador tanto de las arcas eclesiásticas como de los nombramientos obispales cada vez que lo necesitó, lo cual, más allá de la queja formal y pedido explícito del Papa, nunca fue menguado ${ }^{49}$. En este sentido, toda la glosa encumbra la libertas ecclesiae donde la siente atacada.

Ya en la Segunda Partida, a través de la glosa ad verbum «cuchillos» (proemio), López dará, fiel a lo que viene exponiendo, una visión diametralmente opuesta a la de Alfonso sobre las dos espadas: «[...] alter autem est defensionis gradius materialis, in quo non pugnat, sed manus laica in ipso pugnat quando praecipit ecclesiae minister et vterquem est in ecclesia et uterque est in ecclesia» ${ }^{50}$. Nuevamente, el glosador deja de lado el regalismo del rey Sabio para defender una concepción más gelasiana de la teoría de las dos espadas. Así, frente al esfuerzo de Alfonso X por aceptar la teoría de las dos espadas, pero revestirla de igualdad para ambos elementos participantes, el glosador da vuelta atrás con ese razonamiento interrumpiéndolo desde el principio para que quede claro que el lugar de residencia de la espada temporal es la iglesia, y por lo tanto, el uso que dicho poder pueda hacer de ella está siempre supeditado a los intereses del ministerio papal.

En la glosa ad verbum «dignidad», el glosador se dedica con obsecuente método a alabar la figura de Carlos V. Esta glosa posee una explicación muy llana. El contexto, como ya aclaramos más arriba, sobre el que se yergue la edición, alcanza para ver la necesidad de separar a Carlos de los problemas de lo que hoy podemos llamar «querella de las investiduras», pero también de los sucesos de 1527. Esta glosa, que se muestra inocua por su colocación y su contenido, en realidad resume esta batalla por el sentido que emprende López en 1555 una vez cimentada la derrota de Carlos en Europa. Asimismo, uno de los principales flancos a reconstruir es el de la alianza con los estados pontificios. Casi con cierta recaída teleológica debemos adelantar que lo que fue una cercana guerra abierta en tiempos de Felipe II es un síntoma de que esto no alcanzó. Sin embargo, para no perdernos, debemos observar que el objetivo de esta confrontación semántica podría explicarse por la intención de restaurar lazos rotos en otro tiempo con un actor excluyente del marco internacional, el papa. Esto, a su vez, posee dos características de gran importancia. Por un lado, el fracaso de Carlos en su política internacional está atado a su costado imperial (que arrastra a la monarquía española, pero no la subsume). Por otro lado, que el intento de López muestra una preocupación por esa misma situación española frente al mundo, no la del imperio. Además de lo evidente, López revitaliza la figura del Imperio en un momento complicado en términos institucionales ${ }^{51}$. De esta manera, el intento es el de separar las aguas y reinventar una figura respetuosa del papado para promover nuevos ojos a lo que vendrá. En este sentido, la apelación en este comentario a que si Baldo viviera vería que Carlos $\mathrm{V}$ borra las afrentas del

\footnotetext{
${ }^{48}$ Sería un tanto innecesario citar esta glosa pues resulta muy larga y, verdaderamente, es todo un razonamiento ilado que implica presentación y contraste de argumentos. Vamos, por lo tanto, a exponer el resumen de lo que se puede encontrar en la edición de López.

${ }^{49}$ Cf. AYALA MARTÍNEZ, Carlos, «Las relaciones de Alfonso X con la Santa Sede durante el pontificado de Nicolás III (1277-1280)", in Alfonso X el Sabio. Vida, obra y época, 1, Madrid, Sociedad Española de Estudios Medievales, 1989.

50 «De igual modo [la iglesia] no blande la espada de defensa material, sin embargo la mano laica pelea bajo órdenes del ministerio eclesiástico y cada una reside en la iglesia»

${ }^{51} \mathrm{El}$ problema de la inminente abdicación de Carlos y su ausencia prolongada ponen en primer plano la necesidad de la presencia del corpus legal alfonsí en 1555. Con respecto al contexto institucional se pueden ver, entre otros: RODRÍGUEZ-SALGADO, María José, The Changing face of Empire. Charles V, Philip II and Habsburg Authority, 1551 1559, Cambridge, Cambridge University Press, 1988; y DOMÍNGUEZ ORTÍZ, Antonio, La sociedad española en la Edad Moderna, Madrid, Istmo, 2005 y, del mismo, The Golden Age of Spain, 1516-1659, New York, Basic Books, 1971.
} 
pasado entre el imperio y el papado, tiene una fuerte connotación de pacificación sobre un tema que es conflictivo desde hacía muchos siglos. Una vez más, no resulta entonces llamativo que esto aparezca en la primera ley que habla sobre el imperio.

En la glosa ad verbum «espirituales» (P. II, I, 1), nuevamente se expondrá la misma idea que en la glosa de la Partida anterior, refiriendo que existe una preeminencia del Papa en cuestiones temporales. En la glosa ad verbum "privilegio», plantea una retroversión de la jurisdicción de los señores al emperador o al rey: «[...] in terris dominorum, rex fundat intentionem super iurisdictionem, unde ex sola negligentia eorum iurisdictio reuertitur ad ordinariam et regiam a qua emanauit $[\ldots .].\rangle^{52}$. Resulta interesante el hecho de que en esta coincidencia ambos textos, fuente y glosa, refieren a una instancia de cesión de funciones. Dicho de este modo, lo que está en juego no es un tipo de «propiedad» eminente, sino el simple uso o función por parte de un encargado temporal. En rigor, la cuestión de fondo es una reafirmación de autoridad última y absoluta sobre el espacio laico de poder por parte del monarca o emperador en sus territorios. En este sentido, la palabra fundat da muestras del orden en el que se intenta plantear la relación entre jurisdicción y soberanía. En esta glosa no hay contradicción alguna con el texto planteado por Alfonso, sino una reafirmación del contenido del mismo. El objeto de conflicto, en este caso, es el circunstancial poder laico local que pueda levantarse contra el rey o emperador.

\section{Reflexión final}

Muchos elementos podrían haber sido contemplados. Sin embargo, por cuestiones de espacio, y del intento de no agotar con ejemplos al lector, hemos dejado de lado varios aspectos importantes, aunque todos ellos, analizados en otros espacios, han mostrado la misma dinámica por resultado. En los lugares donde Alfonso X no «ataca» el lugar del papado, López reafirma, acepta o ni siquiera comenta, como en el último caso visto. Sin embargo, donde sí se produce el conflicto el glosador se da a la firme contraposición. La manera en la que lo hace es el verdadero objeto de nuestra labor.

En primer lugar, debemos ver la operación sobre la materialidad que realiza. Los extractos expuestos y traducidos no son más que una parte de estas glosas. Las mismas entonces poseen una extensión variable que mantiene cierto promedio en, al menos, media plana de la edición. De este modo, con la colocación de la «llamada» en medio de la perícopa, cortándola sin el más mínimo cuidado, produce un quiebre en la lectura. Este quiebre no solo es evidente: se viene leyendo en un registro y de repente el editor pide observar hacia otro lado. Además, provoca la pérdida de un elemento central de la retórica alfonsí, el cual intentamos definir con férreas pruebas en el penúltimo apartado: la ilación sintáctica. Entonces, el primer elemento sintomático del conflicto por el sentido no está en el cambio semántico por fuerza de contrastar lo dicho con otro dicho, sino en romper el medio principal de transporte del sentido alfonsí, su argumentación trabada. Este recurso muestra un cambio tan grande sobre la materialidad que podría decirse que cambia el texto. Hace propia la obra en todos los sentidos posibles. Así, la publicación de este corpus jurídico tan importante solo sirve de bastidor para el establecimiento de objetivos políticos concretos que responden a un contexto distinto. Esto que parece autoevidente no lo es, pues esta glosa no tiene una implicancia pedagógica de guía o ayuda, de contextualización de un escrito vetusto. El comentario implica la destrucción del texto que, a su vez, lo hace posible reinvirtiendo los roles. El comentario es el texto a publicar por medio del lugar de autoridad que brinda Siete Partidas. La glosa hermenéutica envolvente rompe hasta tal punto la semántica y la sintaxis que la sensación de lectura que provoca no implica conflicto, sino corrección. No es pedagógico, es

\footnotetext{
52 «en las tierras de los señores el rey establece su derecho legal por sobre la jurisdicción, de donde se sigue que de la
} sola negligencia de éstos [los señores] la jurisdicción vuelve a la ordinaria y real [regia], de la cual emanó». 
L'Âge d'or, 8 (2015)

adoctrinador. Las condiciones, las intenciones, y largos etc. no son más que elementos circunstanciales para explicar los porqués. En este trabajo solo quisimos probar, con algunos ejemplos, la manera en la que Partidas proporcionó un marco de legitimidad para una glosa que tenía objetivos y contenido propio. 